\title{
Periscope
}

The dressings are carried out as in the initial operation, i.e., the wound is swabbed out with iodine and packed with petrolatum gauze.

The author emphasises the fact that the presence of a purulent discharge for days or even weeks does no harm. Stiffness in the neighbouring joints found after the removal of the retaining plaster does not result from the immobilisation but can be attributed entirely to inflammation.

Compound fractures are treated in the same manner with calipers enclosed in the plaster, if traction is deemed necessary. One case so treated is cited of a compound comminuted fracture of the lower end of the femur with exposure of the popliteal contents. Complete healing and good functional result was obtained within seven months of the injury.

H. WinnetT ORR, M.D., F.A.C.S., "Listerism-properly and improperly applied in the treatment of Infections of Bones and Joints" (Amer. Journ. Surgery, May 1928, iv., No. 5).

R. L. S.

\section{PRODUCTIVE ENDARTERITIS OF THE SMALL}

CORTICAL VESSELS IN SEVERE TOXÆMIAS.

Normally the lining of the cerebral vessels consists of but a single layer of flat endothelial cells. Nissl and others have found that in syphilis these cells may proliferate, especially the cells of the intima and to a less degree of the adventitia, and partial or complete blocking of the vessels may result. These changes may be limited to the small vessels of the pia and cerebral cortex, and as spirochætes have never been found present, it is concluded that they are probably toxic and not directly bacterial in origin. It is also to be noted that inflammatory changes are likewise absent.

Similar proliferative vascular changes have been described in certain toxic and infectious conditions, non-syphilitic in nature, such as lead, arsenic, carbon monoxide, and mercury poisoning, and in typhoid, typhus, dysentery, pernicious anæmia and tuberculous meningitis.

Two cases are described here, the first in a coloured girl aged 7 years, and the second in a coloured man aged 23 years, who both died from food poisoning, and in both of whom syphilis was absent. In the case of the girl there were marked gastro-intestinal symptoms with low fever, marked prostration and delirium. In the second case the process was more prolonged and symptoms of uræmia developed before death. In both cases the small vessels of the cortex were involved and showed endothelial proliferation with mitosis and new vessel formation. Areas of partial softening were found involving chiefly the occipital and motor areas and evidence of inflammation was absent in both cases.

As both these cases showed marked cerebral symptoms, it is 


\section{Periscope}

suggested that in severe acute infections and intoxications the cerebral symptoms which develop may have their origin in vascular changes of the above type with secondary cortical lesions.

A. N. B.

N. W. Winkelman and J. L. Eckel (Brain, i 927 , 1., pp. 608-623).

\section{MEASLES IMMUNISATION.}

Many organisms have been described as the causal agent of measles and though opinion is not as yet unanimous, the claims of Tunnicliff's micrococcus appear to be enhanced by the present report. In I9I 7 this worker isolated an oryanism from the blood in the pre-eruptive and eruptive stages of measles and later was able to immunise goats. The serum so produced is said to be both antitoxic and antibactericidal. During a recent epidemic of the disease, Halpern employed Tunnicliff's serum and has recently reported his results. Attention was directed to the prevention of measles in a group of fifty children ranging from a few weeks to twelve years of age, none of whom had previously suffered from the disease. They were admitted to a ward in which active cases of measles were present or had very recently been present. Seventeen of these, whose condition definitely excluded a prodromal stage of measles, were immunised with 5 c.c. of serum immediately before admission to the ward. Only three subsequently developed measles. Of the remaining thirty-three cases, many were admitted with a rhinitis, bronchitis or other respiratory infection. They received serum from one to six days after exposure. In this group the results were not so good. Fourteen developed the disease. Twenty-eight patients in all were successfully protected. While seventeen developed the disease, the majority experienced it in an attenuated form. Five patients died from the condition for which they were admitted to the hospital. In spite of the fact that eight patients received serum after the fourth day of exposure, three of these were protected. There were no complications amongst those who were treated with serum and subsequently developed the disease, nor was there any instance of a serum reaction in the entire series.

Louis J. Halpern, "The Prevention and Modification of Measles by Measles Anti-diplococcus Goat Serum" (Journ. Amer. Med. Assoc., 7th April 1928, vol. xc., p. I ro9).

A. R. G.

\section{SCABIES.}

Scabies is so common and the diagnosis ordinarily made with so little difficulty that we are apt to forget that it may be atypical. Brechet describes a small epidemic in a hospital which proved that the disease can be atypical and almost as quickly contracted as an exanthem.

Five babies aged 5 to 10 days contracted an eruption almost VOL. XXXVI. NO. II. 